\title{
Partial Response in Neuroblastoma
}

National Cancer Institute

\section{Source}

National Cancer Institute. Partial Response in Neuroblastoma. NCI Thesaurus. Code C103313.

Fifty to $90 \%$ reduction of primary tumor; $50 \%$ or greater reduction in measurable sites of metastases; 0-1 bone marrow samples with tumor; number of positive bone sites decreased by greater than $50 \%$. 